\title{
Vencer el miedo para recuperar la identidad: el conflicto armado en Colombia y la masacre de Bojayá
}

Juan Pablo Ortiz Ramos

Universidad de Silesia

\section{ViOLENCIA Y CONFLICTO ARMADO}

Hablar de la Colombia de finales del siglo XX e inicios del XXI, es hablar del miedo que genera la muerte y la violencia, representada en ataques, combates, masacres, secuestros, desplazamiento forzado, hostigamientos e intranquilidad; pero también de la historia de miles de personas que, superando su temor, han podido encontrar los mecanismos para recomenzar, partiendo a veces desde cero, forjarse una vida digna de ser vivida y, hacer callar, con su trabajo y optimismo, el sonido de las armas y las bombas.

Es lícito preguntarse, entonces, cómo una nación que "se consume trágicamente en la violencia, ya hereditaria, ya familiar, nacional"1 como consecuencia de haber sufrido el implacable rigor de un conflicto armado de más de cincuenta años de duración, pueda seguir siendo, en palabras del Papa Francisco: "un pueblo alegre entre tanto sufrimiento, (...) un pueblo con

\footnotetext{
${ }^{1}$ Cedeño, Villoria Nolla 2008: 333.
} 
esperanza". ${ }^{2}$ La historiografía de las repúblicas latinoamericanas realizada durante el siglo XIX podría ayudar a entender esta percepción. Y es que la independencia de aquellos pueblos, y Colombia no es la excepción, se fue fraguando al calor de la revolución, con la violencia como protagonista. María Helena Rueda considera que los historiadores de aquella época comprenden la violencia como parte de la vida cotidiana, justificada, en el marco independentista, al sublimar el fin que se pretende alcanzar, es decir, la apología de la nación. ${ }^{3}$ La patria se ha gestado en un ambiente hostil, sin embargo, el derramamiento de sangre de la revolución no es vista desde el sinsentido, todo lo contrario, a partir de la época de la Regeneración, ${ }^{4}$ se enseñó en las escuelas y colegios de Colombia que la violencia era un "mal necesario". Los libros de texto de secundaria utilizados para enseñar la historia de Colombia hasta finales de la década de 1970 lo mostraban con claridad:

En dicha visión heroica los hechos no son percibidos como un problema social en sí mismos. Se habla de guerras, matanzas y revoluciones, pero no de "violencia", como tal. La idea de la nación recoge y contiene los actos de agresión, sin que aparezca una noción de víctimas o victimarios. Los hechos de violencia, por el contrario, proveen el impulso que alienta la construcción de la nación. ${ }^{5}$

El país, por lo tanto, ha estado acompañado, desde su nacimiento, de una violencia que se ha manifestado de diversas maneras. Y aunque no existe homogeneidad en la percepción, legitimidad, vivencia e intensidad de las manifestaciones y expresiones de violencia en Colombia, esta se ha presentado con mayor ímpetu en ciertos periodos específicos de su historia. Un ejemplo claro de ello es la época comprendida desde 1946 hasta $1958,{ }^{6}$ en la cual la zona rural

2 Palabras proferidas en la Audiencia General del miércoles 13 de septiembre de 2017 al hacer un balance de su visita a Colombia realizada del 6 al 10 de septiembre del mismo año; FranCISCO PAPA 2017.

3 Rueda 2008: 349.

${ }^{4}$ La Regeneración fue un movimiento de tipo social político y educativo que surgió a finales del siglo XIX en Colombia. Miguel Antonio Caro fue uno de sus principales inspiradores, pero fue Rafael Núñez, cuatro veces electo presidente de Colombia, quien, en su segundo mandato, se encargó de consolidar el proceso. Precisamente, en este periodo, Núñez promulgo la Constitución de 1886, que duró en vigor más de cien años, hasta ser derogada por la actual carta magna de los colombianos (1991). Dicha constitución y los libros de historia que promovían el patriotismo, fueron los instrumentos privilegiados para lograr la moralización de los colombianos a través del sistema de educación nacional, con el beneplácito y la ayuda de la Iglesia Católica (RUEDA 2008: 350).

${ }^{5}$ RUEDA 2008: 351.

${ }^{6}$ El periodo de 1946 a 1958 está comprendido desde el retiro del presidente liberal Alfonso López Pumarejo hasta el acuerdo bipartidista conocido como Frente Nacional. Algunos historiadores, sin embargo, prefieren hacer coincidir el inicio de este periodo histórico con el asesinato 
colombiana fue el escenario de los enfrentamientos entre liberales y conservadores, que dejaron a su paso una estela de sangre y crueldad. ${ }^{7}$ Como mantiene Murillo "para referirse a tal convulsión y desvarío, los colombianos empezaron a hablar de la Violencia, con mayúscula, y a clamar por la paz". ${ }^{8}$ El hecho de que esta época histórica concreta se conozca como "La Violencia" es un factor determinante al comprender que la etapa, en la que solo se hablaba de revolución y batalla sin referirse a las víctimas y victimarios, estaba a punto de terminar. La escritura es un reflejo claro de ello. La violencia y el miedo que esta genera comenzaron a ser parte de las narraciones escritas. Es así como junto a las llamadas "novelas de violencia", también proliferaron las investigaciones de intelectuales y diversos estudios sobre el tema, conocidos en su conjunto como "violentología", que pretenden alimentar una nueva comprensión de la historia de Colombia. ${ }^{9}$ La nación empieza a tratar de comprender los factores que están determinando el transcurrir de su historia, y a buscar nuevas alternativas y formas de cambiar su destino.

En este marco de referencia se vislumbra la génesis de lo que hoy conocemos como conflicto armado en Colombia. La violencia entre los partidos tradicionales colombianos, el Liberal y el Conservador, se fue transformando progresivamente en violencia subversiva. ${ }^{10}$ Es así como la resistencia, manifestada comúnmente en el país como insurgencia, se va desarrollando bajo el referente del orden social presente en aquella época, con rasgos políticos, culturales y socioeconómicos concretos, que fueron generando exclusión, especialmente, en los sectores rurales. Es pertinente resaltar, entonces, que de todos los factores anteriormente mencionados, el orden capitalista es determinante en la aparición de este tipo de manifestaciones de subversión. ${ }^{11}$ Es así como, tempranamente, empezaron a proliferar dos tipos de modalidades guerrilleras en Colombia: las guerrillas liberales y, en menor medida, las comunistas. Las FARC, el ELN y el EPL" constituyen lo que hoy se conoce como guerrillas de "primera generación”. Otras organizaciones militares subversivas como el M-19, el Quintín

del candidato presidencial liberal Jorge Eliécer Gaitán en abril de 1948. Otros incluso extienden el periodo de manifestaciones y actos de violencia hasta el año de 1966 (MuriLlo PosadA 2011: 291-306).

7 RUEDA 2008: 346.

${ }^{8}$ Murillo Posada 2011: 296.

9 ORTEGA 2008: 368.

${ }^{10}$ GMH 2013: 112.

11 Moncayo Cruz 2016: 12.

${ }^{12}$ El origen de las Fuerzas Armadas Revolucionarias de Colombia (FARC) se remonta a las guerrillas móviles comunistas y a las autodefensas campesinas de los años 50. La conformación, sin embargo, del Ejército de Liberación Nacional (ELN) y del Ejército Popular de Liberación (EPL) es más tardío y se ve influenciado por la ola suscitada en Latinoamérica por la Revolución Cubana (Pizarro LeOngómez 2015: 165). 
Lame, el PRT (Partido Revolucionario de los Trabajadores) y el CRS (Corriente de Renovación Socialista) son conocidas como guerrillas de "segunda generación". Su origen es posterior, hacia la década de los años 70 y 80 , y su desmovilización se produjo entre 1991 y $1994 .{ }^{13}$ En respuesta a la insurgencia guerrillera que, desde el ámbito político militar, se considera de "inspiración marxista con aliento de confrontación y oposición al capitalismo", ${ }^{14}$ nace, bajo diferentes modalidades y, en defensa del sistema establecido, la contrainsurgencia. En un primer momento se presenta bajo la figura de "autodefensas", luego como cooperativas de seguridad, para englobarse, finalmente, en lo que se conoce comúnmente como paramilitarismo. La contrainsurgencia paramilitar, con la convivencia o con la complicidad del estado, permite la estructuración de elites legales e ilegales con principios ideológicos y fines políticos y económicos comunes..$^{15}$ En este momento son tres los actores del conflicto. Por un lado están las Fuerzas Militares y de Policía, por otro los grupos guerrilleros y, en fin, los paramilitares. Si a esto se le suma el entrecruzamiento del narcotráfico con el conflicto armado, obtenemos un panorama poco alentador en Colombia. ${ }^{16} \mathrm{El}$ país se encuentra dividido territorialmente en zonas de dominio de uno u otro de los actores armados, y sumergido en una ola de violencia representada en enfrentamientos, atentados, tomas y ataques a municipios, hostigamientos, masacres, desplazamiento forzado y asesinatos selectivos. Estos fenómenos se desarrollaron principalmente en las áreas rurales de Colombia, afectando, por lo general, a la población civil más pobre y vulnerable. Es, en este contexto, donde ocurre la masacre de Bojayá, descrita como "una de las más grandes tragedias humanitarias de Colombia". ${ }^{17}$

\section{El Atrato: unA zona A la QUe llega el conflicto}

Así se conoce a una subregión del departamento del Choco colombiano bañada por el río que lleva el mismo nombre. El Atrato, pues, está conformado por siete municipios, entre ellos, el de Bojayá, cuyo casco urbano se conoce comúnmente como Bellavista, ubicado en la zona media de la región: el Atrato Medio. ${ }^{18}$

\footnotetext{
13 Pizarro Leongómez 2015: 166-167.

14 Moncayo Cruz 2016: 18.

15 Moncayo Cruz 2016: 18.

${ }^{16}$ GMH 2013: 143.

17 SÁNCHez Gómez 2010: 15.

${ }^{18}$ No se confunda, pues, con el municipio de Medio Atrato, cuya cabecera municipal es Beté; ni con El Atrato, con la población de Yuto como su cabecera municipal. Ambos municipios situados también en el departamento del Chocó.
} 
En esta área del país se ubicó gran parte de la población afrodescendiente colombiana. Se caracteriza por su biodiversidad, considerada como un verdadero tesoro. Sin embargo, la explotación indiscriminada de recursos naturales como la madera, la explotación minera sin control y, la corrupción y abandono del estado, hacen que esa riqueza natural se vea fuertemente contrastada con la pobreza, la violencia y el abandono en el que viven sus habitantes. ${ }^{19}$

En el marco contextual del conflicto colombiano, tal como lo muestra la Agencia de la ONU para los refugiados ${ }^{20}$ la región fue paulatinamente cobrando relevancia, llegando a convertirse en una zona estratégica clave para los actores armados, gracias a ser, por una parte, un corredor que facilita el abastecimiento de armas y, por otro, una salida de droga al extranjero. Es así como a finales de la década de 1980 empiezan a llegar a la zona el M-19, el ELN y las FARC, que se venían enfrentando con los paramilitares en Urabá, Córdoba y Antioquia, y que estaban siendo paulatinamente expulsados de esas regiones. ${ }^{21}$

En Napipí, un corregimiento del municipio de Bojayá, que se encuentra cerca de Bellavista y a la orilla del río Atrato, la violencia de los enfrentamientos entre los actores armados empieza a sentirse con fuerza en el mes de enero de 1997. Allí llegan los paramilitares con el fin de expulsar de la región a los grupos guerrilleros y comienzan a desaparecer o asesinar cruelmente a todos aquellos que consideren sus colaboradores. ${ }^{22}$ La violencia se multiplica y el miedo empieza a hacerse sentir con fuerza en la zona. La gradual avanzada de los grupos de paramilitarismo y el incremento de la presencia de la Fuerza Pública, caracteriza este periodo que se extendió hasta el año 2000. Estos dos actores armados del conflicto parecían convivir sin mayores dificultades, según las denuncias presentadas por la Iglesia y las organizaciones regionales de aquella época. ${ }^{23}$

Es precisamente en aquel año cuando la situación cambia drásticamente para los habitantes de Bojayá. El 25 y 26 de mayo de 2000 la guerrilla se toma en simultánea a Vigía del Fuerte ${ }^{24}$ y Bellavista. El saldo de aquel ataque guerrillero es de 30 muertos, 21 policías y 9 civiles. Entre ellos se encontraba el alcalde municipal de Vigía, Pastor Damián Perea, quien había sido anteriormente acusado de tener nexos con el paramilitarismo. ${ }^{25}$ Ahora era la guerrilla la que dominaba esta zona del Atrato, y los pobladores se quedaban sin la presencia

19 LANCheros RuIZ, Rincón ORTIZ 2007: 445.

${ }^{20}$ ACNUR 2004: 1.

${ }^{21}$ LANCHEROS RuIZ, Rincón ORTIZ 2007: 445.

22 SÁNCHez Gómez 2010: 38.

23 SÁNCHez Gómez 2010: 42.

${ }^{24}$ Vigía del Fuerte es un municipio, muy cercano a Bojayá, ubicado en la zona del Urabá en el departamento de Antioquia. Está separado de Bellavista por el río Atrato.

${ }^{25}$ LANCheros RuIZ, Rincón ORTIZ 2007: 446. 
efectiva del Estado. A decir verdad, la situación para los pobladores no había cambiado tanto, seguía siendo dramática. El dominio había solo pasado de unos a otros. Mientras tanto, la Iglesia era la institución que, en la figura de sus párrocos y misioneras, acompañaba al pueblo. Entre los años 2000 y 2002 los bojayaseños, y todos los habitantes de la región, sufrieron continuas represiones violentas por parte de la guerrilla en su intento de contener la avanzada paramilitar. Esta situación, acompañada algunas veces de la inclemencia de la naturaleza y del río Atrato, generó que se agudizara el desplazamiento forzado. ${ }^{26}$

A finales del mes de abril de 2002, cerca del día 21, 250 paramilitares del bloque Elmer Cárdenas, comienzan a organizar las acciones pertinentes para recuperar la zona y a movilizarse. Dada esta situación, que presenta un escenario ya inminente de confrontación, organizaciones como, la Defensoría del Pueblo, la Procuraduría General de la Nación, la Diócesis de Quibdó y algunas Organizaciones No Gubernamentales, empiezan a emitir alertas tempranas al Gobierno colombiano para que actúe y evite una catástrofe mayor de la que ya se vive en la zona. Sin embargo, las alertas parecen no ser escuchadas, y los paramilitares en pangas ${ }^{27}$ navegan por el Atrato, llegando hasta Vigía del Fuerte. ${ }^{28}$ Con la llegada de este grupo paramilitar la guerrilla se empezó a replegar en la zona rural de los dos municipios, pero sin retirarse. La confrontación era ya algo inevitable.

\section{EL RÍO SE TIÑE DE SNAGRE...}

Los habitantes de Bojayá al ver llegar a alias "Camilo" jefe de una de las compañías paramilitares, se prestaron a leerle la llamada "Declaración por la Vida y por la Paz", un documento que pretende dejar por fuera de la confrontación a la población civil, pidiendo respeto por los lugares habitados y los sitios de encuentro común. ${ }^{29}$

El primero de mayo, muy temprano en la mañana, "Camilo" fue herido de gravedad por la guerrilla, mientras se transportaba en una panga junto a unos veinte de sus hombres. ${ }^{30} \mathrm{El}$ hecho suscitó que, hacia las nueve de la mañana,

26 SANCHEZ Gómez 2010: 43-44.

27 La panga es una embarcación pequeña, generalmente movida a motor, que puede lograr una gran velocidad. Su capacidad es aproximadamente de 15 personas, y es muy utilizada en el transporte fluvial por el río Atrato.

28 SANChez Gómez 2010: 44-48.

29 SANCHez Gómez 2010: 48-51.

30 SANCHez Gómez 2010: 51. 
los frentes 5 y 57 del Bloque José María Córdoba de las FARC siguieran avanzando. ${ }^{31}$ La confrontación se desarrolló, en un primer momento, en la zona rural de los municipios, pero no pasó mucho tiempo para que se desplazara a puntos más estratégicos como el casco urbano, en este caso Bellavista.

Las casas de los habitantes del municipio eran humildes, hechas de madera, con unos pilotes que les servían de base y las resguardaban cuando el río se desbordaba e inundaba el casco urbano. Una solución ingeniosa, que los protegía del agua, pero no de las balas. Es por eso, que la mayoría de los pobladores, al arreciar los disparos, y ya entrada la noche, corrieron a refugiarse en una de las tres edificaciones de material con las que contaba la cabecera municipal, a saber: el templo parroquial San Pablo Apóstol, la casa de las Hermanas Agustinas y la casa cural. La mayoría de las personas se dirigió hacia la iglesia, como acotan Lancheros Ruiz y Rincón Ortiz "por ser la edificación de cemento más grande y por tratarse de un lugar sagrado" y, "a nadie le pasó por la cabeza que fueran a irrespetar el templo, a nadie se le ocurrió que meterse allí marcaría el último día de sus vidas". ${ }^{32}$ Es así como alrededor de 300 personas, niños y ancianos incluidos, pasaron esa terrible noche de angustia en el templo. ${ }^{33}$ Los acompañaban el párroco, el padre Antún Ramos, y otros dos sacerdotes, quienes trataban de gestionar lo inmanejable.

A la mañana siguiente, después de una breve tregua no concertada, un poco antes de las diez, la guerrilla instaló dos lanzadores de cilindros bomba. ${ }^{34}$ A pesar del riesgo que implicaba lanzar estos artefactos contra objetivos en movimiento, los guerrilleros recibieron la orden de lanzar las pipetas. Fueron un total de cuatro. La primera explotó cerca de la iglesia, a unas cuantas decenas de metros de distancia. La segunda y la cuarta cayeron sin explotar, una en el patio trasero del puesto de salud, cerca de la casa cural, la otra detrás de la casa de las Hermanas Agustinas. Sin embargo, el tercer cilindro rompió el techo del templo parroquial, y se coló hasta impactar con el altar, explotando en medio de todos los allí guarecidos. ${ }^{35}$

Lo que siguió fue una imagen apocalíptica. En palabras de Lancheros Ruiz y Rincón Ortiz: "gente desmembrada buscaba la salida; se oían llantos,

31 LANCHEROZ RuIz, Rincón ORTIZ 2007: 444.

32 LANCheroz Ruiz, Rincón OrTiz 2007: 449.

33 SANCHEz Gómez 2010: 57.

${ }^{34}$ Los cilindros bomba consisten en una pipeta de gas común trasformada en un artefacto explosivo no convencional. Normalmente el cilindro se encuentra relleno de explosivos y metra1la. La metralla está compuesta por pequeños pedazos de metal que causan heridas contundentes al ser expulsados violentamente en el momento de la explosión. Los lanzadores de estas pipetas normalmente son rudimentarios y no ofrecen un control adecuado, ni de la dirección, ni del lugar de la explosión del cilindro.

35 SÁNCHez Gómez 2010: 58-59. 
gritos, clamores de angustia; quienes se daban cuenta de que estaban vivos reaccionaban ante sus heridas y corrían despavoridos". ${ }^{36}$ Se contaron en total 119 víctimas mortales, de ellas, 49 niños y 70 adultos. ${ }^{37}$

Al oír la explosión y ver lo sucedido, las personas que estaban en la casa cural y, sobretodo, en la casa de las Agustinas, comenzaron a temer que allí detonara otro de los cilindros y salieron corriendo en medio del fuego cruzado, que no se detuvo, ni siquiera, ante la masacre apenas ocurrida. En medio de tanta confusión, el padre Antún sacó fuerzas de su debilidad e incitó a los sobrevivientes a reunirse en la parte de atrás de la vivienda de las misioneras. Sabiendo que la única manera de no morir en medio del caos reinante era buscar la salida hacia Vigía del Fuerte, las personas improvisaron banderas blancas con cualquier prenda o trozo de tela y, bajo la guía del párroco, comenzaron a avanzar en medio de los disparos buscando recorrer los 150 metros que los separaban de la orilla del Atrato. ${ }^{38}$ En ese momento se hicieron reconocer como población civil agitando sus banderas y, arriesgándose a la muerte, para escapar de ella, daban un paso tras otro gritando con la poca fuerza que les restaba: "¿Qué somos? Población civil. ¿Qué exigimos? El respeto por la vida" ${ }^{39}$ Es así como, por fin, lograron llegar al borde del río para atravesarlo y embarcarse, en los botes disponibles, hacia Vigía, lejos de aquel infierno, sin más remedio que dejar atrás a sus muertos y a los heridos de gravedad que no pudieron transportar. ${ }^{40}$ Los enfrentamientos se prolongaron hasta el martes 7 de mayo, día en que las Fuerzas Militares retomaron el control de las cabeceras municipales de Vigía del Fuerte y Bojayá. ${ }^{41}$

Fueron pocos los bojayaseños que, después de estos acontecimientos, decidieron permanecer en Vigía. Con Bellavista destruida y, habiendo perdido a sus seres queridos y los pocos bienes materiales que poseían, la mayoría decidió desplazarse hacia las zonas urbanas más cercanas, con la esperanza de algún día volver a su tierra.

36 Lancheroz Ruiz, Rincón Ortiz 2007: 452.

37 LANCHEROZ Ruiz, Rincón OrTIZ 2007: 451. En los relatos testimoniales se presentan un total de 119 muertos. Sin embargo, las fuentes oficiales y las víctimas plenamente identificadas presentan un número sensiblemente inferior, de 79 personas muertas (Gómez NADAL 2012: 10).

38 SÁNCHEZ Gómez 2010: 60-61.

39 LANCheroz Ruiz, Rincón OrTiz 2007: 452.

40 SÁNCHez Gómez 2010: 61-62.

41 LANCheroz Ruiz, Rincón OrTiz 2007: 459. 


\section{RECUPERANDO LA IDENTIDAD}

Las culturas afrodescendientes que habitan el Atrato chocoano, tienen tradiciones muy concretas y diferenciadas sobre el tránsito de la vida a la muerte. ${ }^{42}$ Son parte de su identidad profunda y los conecta a sus ancestros. En la época de la esclavitud, la muerte constituía la forma de paso hacia la liberación definitiva y la superación del sufrimiento provocado por el hombre blanco. ${ }^{43}$ Por eso era tan importante celebrarla. Según la tradición, los adultos y los ancianos son guardianes de la sabiduría tradicional, y al morir, se convierten en ancestros protectores. Cuando la muerte es fruto de la violencia, este camino se interrumpe abruptamente. Por eso son tan importantes los rituales funerarios. Los velorios, la misa de las nueve noches, los adulatorios, las oraciones, los alabaos, los responsorios, el paseo del muerto por la calle y la tumba digna, restablecen el equilibrio entre este mundo y el del más allá. ${ }^{44}$ En el caso de los niños, los alabaos se reemplazan con chigualos o gualíes donde "el cuerpo sin vida del pequeño se alza y se pasa de mano en mano mientras se canta, se baila y se juega con él". ${ }^{45}$ De esta manera se logra que "los niños fallecidos se conviertan en ángeles y querubines protectores". ${ }^{46}$

El pueblo tuvo que huir de la barbarie y, aunque intentó cumplir con su deber hacia sus muertos, no lo logró. ${ }^{47}$ Después de refugiarse en Vigía del Fuerte el jueves de la masacre, los bojayaseños le pidieron a las FARC, al día siguiente, el permiso de retornar a Bellavista para socorrer a cualquier posible sobreviviente y para enterrar a sus muertos. Después de atender a los heridos, los cinco voluntarios que habían emprendido esta importante empresa, se dispusieron a la sepultura, pero encontraron el cementerio inundado. Entonces abrieron una fosa en las afueras del casco urbano para depositar a las víctimas, una tarea para nada fácil, vista la condición de los restos mortales, después de una explosión tan brutal, y de las fuertes lluvias. Lograron sepultar algunos de ellos, pero cuando estaban en medio de esta labor y, teniendo 51 cadáveres depositados en bolsas negras sobre una panga a la orilla del río listos para ser transportados a otra fosa, los enfrentamientos se reanudaron, y no tuvieron más remedio que escapar y dejar, de nuevo, a sus muertos abandonados. ${ }^{48} \mathrm{El}$ lunes 6 de mayo la comisión regresó de nuevo al casco urbano y terminó la sepultura de

\footnotetext{
42 SÁNChez Gómez 2010: 101.

${ }^{43}$ Lancheroz Ruiz, Rincón OrTiz 2007: 460.

44 Lancheroz Ruiz, Rincón OrTiz 2007: 459.

45 LANChEROZ RuIZ, Rincón ORTIZ 2007: 460.

46 SÁNCHEZ Gómez 2010: 102.

47 Sánchez Gómez 2010: 102.

48 LANCHEROZ Ruiz, Rincón ORTIZ 2007: 453.
} 
los cuerpos que se encontraban aún, al borde del Atrato, e intentaron "recoger los cadáveres que quedaban en el templo". ${ }^{49}$ Un mes después, las autoridades ordenaron el traslado de los restos al cementerio de Bellavista, pero, después de tanto tiempo, la identificación de todos los cuerpos no fue posible, y terminaron enterrándolos en bolsas de plástico con una cruz y un número en cada tumba. Los bojayaseños no pudieron identificar plenamente a sus seres queridos muertos, y no cumplieron con los ritos funerarios propios de su cultura. Es como si ellos los hubieran abandonado, dejándolos al "arbitrio de los armados". ${ }^{50}$

Un año después de la masacre, las comunidades empezaron lentamente a retornar a sus tierras y a sus casas. Pero para vencer el miedo es necesario recuperar la esencia, la identidad cultural. Es por eso que, bajo la guía de líderes comunitarios como Leiner Palacios, se creó el Comité por los Derechos de la Víctimas de Bojayá para luchar en pos de la identificación de los cuerpos y de la entrega de los restos mortales a cada familia.

En el marco de los diálogos de paz de la Habana entre el Estado colombiano y las FARC, y con la ayuda de organizaciones como la Comisión de Derechos Humanos de las Naciones Unidas, el Comité logró que comenzara el 4 de mayo de 2017 la exhumación de las víctimas de la masacre. El proceso terminó el 7 de junio, y los restos fueron trasladados a la ciudad de Medellín para ser identificados y devueltos a sus familias, en el mes de octubre de 2018. Cuando esto suceda se podrán realizar los ritos funerarios correspondientes a sus costumbres ancestrales y se restablecerán los lazos naturales entre los vivos y los muertos, permitiendo que unos y otros recobren por fin la paz.

\section{ReCUPERANDO LA VOZ}

Como se mencionó anteriormente, dentro de los ritos mortuorios propios de las comunidades afrodescendientes del Chocó, se encuentran los alabaos. Como su nombre lo indica, nacen en la alabanza religiosa, pero se consolidan en el ámbito mortuorio. Son, en esencia, "cantos ceremoniales fúnebres de transición de los muertos para que hallen el camino al otro mundo y se reencuentren con sus ancestros". ${ }^{51}$ Esta antigua tradición de las comunidades del Pacífico colombiano, tiene su origen en los romanceros españoles. En la época del colonialismo español en América, se les enseñaba a los esclavos el idioma y la religión con este tipo de poemas. Por consiguiente, la cultura y la religión española y

\footnotetext{
49 LANCheroz Ruiz, Rincón OrTiz 2007: 457.

${ }^{50}$ SÁNCHEZ GómEz 2010: 101.

51 SÁNChez Gómez 2010: 103.
} 
africana se fueron sincretizando, y los esclavos africanos adaptaron los cantos $\mathrm{y}$ las historias a la memoria de sus ancestros. ${ }^{52}$

Los alabaos son, regularmente, cantos femeninos, y las alabaoras son las encargadas de entonarlos. No pueden ser cantados por una sola mujer, ya que son manifestaciones colectivas que poseen un ritmo específico, carácter responsorial y que requieren del encuentro de las involucradas; ellas son, normalmente, de distintas generaciones y procedencias, y logran construir relaciones mutuas muy sólidas. Solo así el canto es conmovedor y la emisión de la voz tiene la fuerza necesaria. De esta manera, las alabaoras consiguen "hacer efectiva la práctica de acompañar a muertos y a dolientes, elaborar el duelo y recuperarse de las pérdidas". ${ }^{53}$

Esta práctica ancestral une a las comunidades en torno a la experiencia de la muerte, que para ellos siempre representa una experiencia colectiva, con la participación de todos sus miembros. Facilita, pues, la elaboración del duelo de los parientes más cercanos y estrecha los lazos de unión y solidaridad en la comunidad. Sin embargo, si la muerte es producto de un acto violento, el alabao adquiere un aire de denuncia. Esto genera que la unión de la comunidad no se realice únicamente en torno al sufrimiento y al dolor, sino al compromiso social y a la responsabilidad y participación ciudadana. ${ }^{54}$

¿Cómo cantarle a la muerte cuando el miedo generado por una masacre como la de Bojayá te deja sin voz? ¿Cómo hace una comunidad para expresarse en medio del sonido de las balas que pretenden hacerla callar? La guerra normalmente trae como consecuencia el silencio y la muerte. ${ }^{55}$ Sin embargo, las alabaoras de Pogue,${ }^{56}$ con su voz, pretenden sustituir este binomio por el de muerte y canto. La muerte (aquella que pudo ser evitada) y el canto (en forma de denuncia), dos pilares con los que contribuyen, desde su tradición ancestral, en la construcción de una paz duradera.

Las Musas de Pogue es el nombre con el que se conoce a las alabaoras de Bojayá. Son reconocidas en toda la región, y con dignidad, han mantenido la tradición fúnebre de sus comunidades. Es por eso que de otros municipios de la zona las mandan llamar para cantar en los actos mortuorios. ${ }^{57}$ Pero la crueldad e intensidad del conflicto armado hacen que la muerte tome otras dimensiones, al igual que su canto. Estas mujeres, como ha sucedido en otras partes de Colombia, "no han sido sujetos pasivos ante las circunstancias que rodean sus

\footnotetext{
52 Quicena Toro, Ochoa Sierra, Villamizar 2007: 181.

53 Quicena Toro, Ochoa Sierra, Villamizar 2007: 181.

${ }^{54}$ Quicena Toro, Ochoa Sierra, Villamizar 2007: 184.

55 Quicena Toro, Ochoa Sierra, Villamizar 2007: 184.

${ }^{56}$ Pogue es uno de los 15 corregimientos del municipio de Bojayá.

${ }^{57}$ Quicena Toro, Ochoa Sierra, Villamizar 2007: 181.
} 
vidas". ${ }^{58}$ La voz que emerge de la garganta de las Musas ha adquirido, con el pasar de esta guerra sin sentido, una fuerza relevante; ahora sus cantos "fundan un proyecto político de denuncia en la oralidad y el arte". ${ }^{59}$ Este proyecto las ha llevado a componer, narrar y denunciar, con sus cantos, lo ocurrido el día de la masacre. Estos alabaos ahora se conocen con el nombre de "composiciones para la memoria" ${ }^{60}$ Un ejemplo claro de ello es la composición de Ereiza Palomeque, hecha en el 2014, titulada: "Esto quedo en el oscuro". Riaño y Chaparro (2016), citados en N. Quiceno Toro, M. Ochoa Sierra y A. M. Villamizar, ${ }^{61}$ nos presentan un fragmento del texto:

El día 2 de mayo una pipeta cayó, ¡Ay!, cayó dentro de la iglesia, el cristo lo mutiló.

Esto quedó en el oscuro de la bala desplotada, como corría el agua y era sangre derramada

El 9 de abril de 2016, fecha en la que se celebró el Día Nacional de la Memoria y la Solidaridad con las Víctimas del conflicto armado en Colombia, las alabaoras de Pogue fueron invitadas a cantar en un acto organizado en Bogotá, alrededor del Museo de la Memoria; y, sin poderlo anticipar, terminaron en la Casa de Nariño cantándole de frente, y con la frente en alto, a Juan Manuel Santos, presidente de la República. ${ }^{62}$ Más adelante, tuvieron la oportunidad de entonarle sus alabaos a sus victimarios, en medio de su comunidad y en el lugar mismo de la tragedia, cuando las FARC realizaron un acto público para pedir perdón por la masacre. Pero tal vez, lo más representativo sucedió en Cartagena, durante el acto de la firma del acuerdo de paz entre las FARC y el Estado el 26 de septiembre de 2016. El acto contó, no solo con la presencia de los protagonistas del acuerdo, sino con una participación nutrida de organizaciones y autoridades nacionales e internacionales y fue transmitido en directo para varios lugares del mundo. Ese día las alabaoras de Bojayá le cantaron y le contaron al mundo entero su historia y lograron exorcizar, de algún modo, el fantasma del miedo de aquellas víctimas que se ven obligadas a guardar silencio.

\footnotetext{
58 SÁNCHEZ Gómez 2010: 15.

59 Quicena Toro, Ochoa Sierra, Villamizar 2007: 185.

${ }^{60}$ Quicena Toro, OchoA Sierra, Villamizar 2007: 186.

${ }^{61}$ Quicena Toro, Ochoa Sierra, Villamizar 2007: 188.

${ }^{62}$ Quicena Toro, Ochoa Sierra, Villamizar 2007: 190.
} 
Es así, como estos humildes campesinos, sin quererlo, se han convertido en protagonistas de un conflicto que no les pertenece y que quieren desterrar de raíz de sus comunidades. Pasaron de ser víctimas silenciosas a ser garantes de una paz que todos los colombianos anhelan posible. Ellos han recuperado su identidad y su voz en medio de un conflicto armado que los sigue persiguiendo, y que por ahora, parece seguir formando parte de su cotidianidad.

\section{Bibliografía}

ACNUR - Agencia de la ONU para los Refugiados (ACNUR), "Algunos indicadores sobre la situación de los derechos humanos en la región de Atrato", $A C N U R, 2014$, documento html disponible en: <http://www.acnur.org/t3/uploads/media/677.pdf?view=1>, (consultada: 17/12/2017).

CASTAÑEDA 2002 - Nubia Castañeda, La resistencia desde la espiritualidad. El caso de Bojayá, "En otras palabras" (Universidad Nacional de Colombia), 11 (2002), pp. 81-87.

Cedeño, Villoria Nolla 2008 - Jeffrey Cedeño, Maite Villoria Nolla, Violentamente Colombia, "Revista Iberoamericana" (Instituto Internacional de Literatura Iberoamericana), 223 (2008), pp. 333-341.

Francisco PAPA 2017 - Francisco Papa, Audiencia general miércoles 13 de septiembre de 2017, "La santa sede", 2017, documento html disponible en linea: <https://w2.vatican.va/content/francesco/es/audiences/2017/documents/papa-francesco_20170913_udienza-generale. html>, (consultada: 15/11/2017).

GMH 2013 - Grupo de Memoria Histórica (2013) ¡BASTAYA! Colombia: Memorias de guerra y dignidad. Bogotá: Imprenta Nacional.

Gómez NadAl 2012 - Paco Gómez Nadal, Los muertos no hablan, Medellín: Editorial Nuevo Milenio 2012.

Lancheros Ruiz, Rincón OrTiz 2007 - Aída Carolina Lancheros Ruiz, Julián Andrés Rincón Ortiz, Entre el miedo y los medios, en: Claudia Mosquera Rosero-Labbé, Luiz Claudio Barcelos (eds.) Afroreparaciones: memorias de la esclavitud y justicia reparativa para negros, afrocolombianos y raizales, Bogotá: Centro de Estudios Sociales 2007, pp. 443-466.

Moncayo Cruz 2016 - Víctor Manuel Moncayo Cruz, Hacia la verdad del conflicto: insurgencia guerrillera y orden social vigente, Bogotá: Espacio Crítico 2016. 
Murillo Posada 2011 - Amparo Murillo Posada, "La modernización y las violencias (1930-1957), en: Luis Enrique Rodríguez Baquero, Ana Luz Rodríguez González, Historia de Colombia. Todo lo que hay que saber, Bogotá: Prisa ediciones, 2011, pp. 291-306.

Ortega 2008 - Francisco Ortega, Sin orden ni final. Escritura y desastre. Representación de la violencia en Colombia, "Revista Iberoamericana" (Instituto Internacional de Literatura Iberoamericana), 223 (2008), pp. 361-378.

Pizarro Leongómez 2015 - Eduardo Pizarro Leongómez, Una lectura múltiple y pluralista de la historia. Comisión de historia del conflicto y sus víctimas, "Academia Libre" (Universidad Libre - Barranquilla), 12 (2015), pp. 151-213.

Quiceno Toro, Ochoa Sierra, Villamizar 2007 - Natalia Quiceno Toro, María Ochoa Sierra, Adriana Marcela Villamizar, La política del canto y el poder de las alabaoras de Pogue (Bojayá, Chocó), "Estudios Políticos" (Universidad de Antioquia), 51 (2007), pp. 175-195.

Rueda 2008 - María Elena Rueda, Violentamente Colombia, "Revista Iberoamericana" (Instituto Internacional de Literatura Iberoamericana), 223 (2008), pp. 345-359.

SÁNCHez Gómez 2010 - Gonzalo Sánchez Gómez (coord.), Bojayá: La guerra sin límites, Bogotá: Distribuidora y Editora Aguilar, Altea, Taurus, Alfaguara, S.A.

SÁNCHez Gómez 2011 - Gonzalo Sánchez Gómez (coord.), Mujeres que hacen historia. Tierra, cuerpo y politica en el caribe colombiano, Bogotá: Distribuidora y Editora Aguilar, Altea, Taurus, Alfaguara, S.A.

\begin{abstract}
Summary
Overcoming the fear of recovering the identity: the armed conflict in $\mathrm{Co}$ lombia and the Bojayá massacre

This article demonstrates the violence in Colombia as a background to the historical events in the country and the way it led to the armed conflict which lasted for over the fifty years. This war continued, with the involvement of the Military Forces of Colombia, the police, the guerrilla and the paramilitary until it reached El Atrato, a very poor and vulnerable part of the country. That is where the massacre of Bojayá took place, one of the most violent acts in the recent history of Colombia. The outcome was a high rate of victims and countless number of stories full of pain and misery. However, the survivors, against all odds, started to overcome the fear and recover. In their culture abandoning the corpse
\end{abstract}


was not accepted. In consequence, they started to fight for their ideals. The article focuses on the way the inhabitants of Bojayá regained their identity and their owning to strong bonds and traditions. It has been written based on academic research and on the leadership that the victims have achieved in the public and mass media field in Colombia. They managed to get the mortal remains of the members of their community exhumed and transferred to Medellin to be identified and, in front of their executioners and in front of the world, they sang their alabaos, they could tell their story that denounced the barbarism and demanded a better future.

Keywords: fear, the armed conflict in Colombia, the Bojayá massacre, victims, alabaos

\section{Streszczenie}

Przezwyciężyć strach, aby odzyskać tożsamość: konflikt zbrojny w Kolumbii i masakra w Bojayá

Prezentowany artykuł ukazuje przemoc w Kolumbii jako nieodłączną towarzyszkę historii tego kraju, a także wyjaśnia, w jaki sposób przekształciła się ona $\mathrm{w}$ ponad pięćdziesięcioletni konflikt zbrojny. Ta walka pomiędzy siłami zbrojnymi i policją z jednej a bojówkami i oddziałami paramilitarnymi z drugiej strony rozgrywała się w różnych miejscach, aż dotarła do biednych i marginalizowanych terenów Atrato. To tam doszło do masakry w Bojayá, jednego z najdrastyczniejszych epizodów we współczesnej historii Kolumbii, który pozostawił po sobie wielu zabitych, a także niezliczoną ilość bólu i rozdarcia. Jednakże pomimo ponurych prognoz ofiary tego wydarzenia zaczęły przezwyciężać swój strach i odzyskiwać sens życia. Ich tożsamość kulturowa nie pozwoliła im pozostawić zmarłych bez pochówku. Wówczas zdecydowali się walczyć o swe ideały. Dzięki badaniom naukowym oraz znaczeniu, jakie nadano ofiarom w publicznej i medialnej rzeczywistości Kolumbii, mieszkańcy Bojayá, tak emocjonalnie związani ze swymi tradycjami, mogli wreszcie odzyskać swój głos i tożsamość. Udało im się doprowadzić do ekshumowania i przewiezienia doczesnych szczątków członków ich wspólnoty do Medellín celem ich identyfikacji, a oni sami stanęli przed swoimi oprawcami i przed całym światem, by wykrzyczeć swój żal oraz opowiedzieć swoją historię, potępiając barbarzyństwo i domagając się lepszej przyszłości.

Słowa kluczowe: strach, konflikt zbrojny w Kolumbii, masakra w Bojayá, ofiary, alabaos 